\title{
Caracterização agronômica e bromatológica de híbridos de milho para ensilagem
}

\section{Agronomic and chemical characteristics of hybrid corn to ensiling}

\author{
Flávia Borges de Assis ${ }^{1}$; Fernanda Carvalho Basso ${ }^{1 *}$; Erika Christina Lara ${ }^{1}$; \\ Elisamara Raposo ${ }^{1}$; Liandra Maria Abaker Bertipaglia ${ }^{2}$; Leonardo de Oliveira \\ Fernandes $^{3}$; Carlos Henrique Silveira Rabelo ${ }^{1}$; Ricardo Andrade Reis ${ }^{4}$
}

\section{Resumo}

Objetivou-se avaliar as características agronômicas e químico-bromatológicas de híbridos de milho para ensilagem. Os tratamentos avaliados foram nove híbridos de milho (MX 300, RB 9308, 2B655, XB 6012, GNZ 2500, PL6890, PRE 32D10, PRE 22 T10 e AG 1051), com três repetições. As maiores produções de MV foram verificadas nos híbridos PL6890 e PRE 32D10, enquanto a maior produção de MS foi observada no híbrido PRE 32D10 (13,43 t ha-1). Os híbridos PRE 32D10 e PRE 22T10 destacaram-se por apresentarem maior porcentagem de lâminas foliares em relação à planta inteira, enquanto a menor porcentagem de colmos foi encontrada nos híbridos MX 300, 2 B655 e XB 6012, entretanto a maior relação folha:colmo foi verificada no híbrido XB $6012(0,49)$. Observou-se maior teor de PB no híbrido PRE 32D10 (9,10\% da MS), enquanto o menor teor de FDN (57,78\% da MS) e celulose $(24,27 \%$ da MS) foram verificados no híbrido GNZ 2500. O híbrido PL6890 apresentou maior teor de FDA $(39,20 \%$ da MS) e lignina $(8,63 \%$ da MS), os demais híbridos apresentaram valores inferiores. Verificou-se menor N retido na FDN (NIDN) no híbrido RB 9308, enquanto a menor retenção de N em FDA (NIDA) ocorreu no híbrido 2B655. A menor capacidade tampão (CT) foi verificada no híbrido 2B655 $(0,29)$. Embora haja diferenças na composição químico-bromatológica dos híbridos de milho avaliados neste estudo, recomenda-se utilizar os híbridos MX 300, PL6890 e PRE 32D10 por apresentarem produção de matéria seca mais elevada, os quais podem refletir na amortização dos custos na produção das silagens.

Palavras-chave: Parede celular, população de plantas, produtividade, Zea mays

\begin{abstract}
Our aim was to evaluate agronomic and chemical characteristics of corn hybrids to ensiling. It were evaluated nine corn hybrids (MX 300, RB 9308, 2B655, XB 6012, GNZ 2500, PL6890, PRE 32D10, PRE 22T10 e AG 1051), with three replicates. The higher fresh matter yield were observed in the hybrids PL6890 and PRE 32D10, while the dry matter yield was observed in the hybrid PRE 32D10 (13.43 $\mathrm{t} \mathrm{ha}^{-1}$ ). The hybrids PRE 32D10 and PRE 22T10 stood out to present higher percent of leaf in relation to whole plant, while the lower percent of stems was found in the hybrids MX 300, 2B655 and XB 6012, however the higher leaves: stems relation was found in XB 6012 (0.49). There was higher CP

\footnotetext{
${ }^{1}$ Discentes, Dept ${ }^{\circ}$ de Zootecnia, Universidade Estadual Paulista "Júlio de Mesquita Filho", UNESP, Jaboticabal, SP. E-mail: flaviabassis@gmail.com; fcarvalhobasso@yahoo.com.br; erikalarac@gmail.com; foxelisa@gmail.com; carlos.zoo@hotmail. com

${ }^{2}$ Prof $f^{\text {. }}$, Universidade Camilo Castelo Branco, UNICASTELO, Descalvado, SP. E-mail: liandramab@terra.com.br

${ }^{3}$ Pesquisador, Empresa de Pesquisa Agropecuária de Minas Gerais, EPAMIG, Uberaba, MG. E-mail: leonardo@epamiguberaba. com.br

${ }^{4}$ Prof., Dept ${ }^{\text {o }}$ de Zootecnia, UNESP, Jaboticabal, SP. E-mail: rareis@fcav.unesp.br

* Autor para correspondência
} 
content in the hybrid PRE 32D10 (9.10\% of DM), while the lower NDF (57.78\% of DM) and cellulose content (24.27\% of DM) were observed in the hybrid GNZ 2500. The hybrid PL6890 presented higher ADF and lignin contents, the others hybrids had values lower. The lower NDIN content was observed in the hybrid RB 9308, while the lower AIDN content occurred on the hybrid 2B655. The lower buffer capacity was observed in the hybrid 2B655 (0.29). There are some differences on chemical composition among the corn hybrids used in this study, however, it is recommended to use the hybrids MX 300 , PL6890 and PRE 32D10 for showing higher dry matter yield, which may reflect in the amortization of silage production costs.

Key words: Cell wall, plant population, yield, Zea mays

\section{Introdução}

Devido à baixa oferta de forragem aos animais em regime de pastejo durante a época seca do ano, problema este que abrange boa parte do território brasileiro, há a necessidade de produzir e conservar alimentos de qualidade para serem utilizados neste período. Portanto, a conservação de forragens na forma de silagem é necessária a fim de manter os níveis de produção animal adequado ao longo do ano e, entre as forrageiras mais utilizadas neste processo, sem dúvida o milho apresenta grande destaque por produzir elevada quantidade de matéria seca, adequado aporte de nutrientes para fermentação e baixa capacidade tampão (MCDONALD; HENDERSON; HERON, 1991).

De acordo com Rosa et al. (2004), a falta de informações regionais pertinentes ao comportamento agronômico produtivo e valor nutritivo dos diversos materiais genéticos existentes no mercado, tornou-se um obstáculo para o melhor planejamento da escolha dos híbridos de milho que se destinem à produção de silagem, sendo fundamental caracterizar os materiais genéticos disponíveis no mercado. Desta forma, a identificação de plantas mais adaptadas às condições em que serão cultivadas pode contribuir para maiores rendimentos da cultura do milho, ressaltando que, além da genética, a produção é influenciada por outros fatores inerentes ao manejo da cultura, como adubação, espaçamento utilizado no plantio e irrigação (ALMEIDA FILHO et al., 1999).

Neste sentido, pesquisas que comparam híbridos são fundamentais para o avanço dos programas de melhoramento genético (ROSA et al., 2004), sendo que as características mais desejáveis para ensilagem são as elevadas produtividades de massas, altas concentrações de energia (alta digestibilidade), teor de matéria seca adequado ( 30 a $37 \%$ ) no momento da colheita para favorecer a compactação da massa e fermentação, além da baixa concentração de fibra (PAZIANI et al., 2009).

Desta forma, a escolha do híbrido a ser utilizado certamentecontribuideformamarcanteparamelhorar a qualidade das silagens produzidas, sendo que, a avaliação dos mesmos quanto ao desenvolvimento agronômico é de suma importância. Portanto, objetivou-se avaliar as características agronômicas e químico-bromatológicas de diferentes híbridos de milho utilizados para ensilagem.

\section{Material e Métodos}

$\mathrm{O}$ experimento foi conduzido durante a safra 2008/2009 na Faculdade de Ciências Agrárias e Veterinárias da UNESP, campus de Jaboticabal - SP. O município está localizado a $21^{\circ} 15^{\prime} 22^{\prime \prime} \mathrm{S}$ e $48^{\circ} 18^{\prime} 58^{\prime \prime} \mathrm{W}$, com altitude média de $595 \mathrm{~m}$ e possui clima tropical chuvoso (Awa) de acordo com a classificação climática de Köppen, apresentando inverno seco (abril a setembro) e verão chuvoso (outubro a março). A média histórica do município quanto à temperatura e precipitação são $22,2^{\circ} \mathrm{C}$ e 1424,6 mm, respectivamente. As condições climáticas em que foi desenvolvido o experimento estão representadas na Tabela 1.

O experimento teve início em dezembro de 2008 com a preparação do solo, classificado como Latossolo vermelho distrófico de textura argilosa 
(EMBRAPA, 2006). A caracterização química está apresentada na Tabela 2. Utilizou-se o sistema de manejo convencional, com uma aração (arado de disco) e duas gradagens (grade destorroadora e niveladora). Posteriormente à análise de solo, procedeu-se à adubação da área com base nas exigências da cultura, aplicando-se $300 \mathrm{~kg} \mathrm{ha-1}$ do formulado NPK 8-20-20 no momento da semeadura, ocorrido em janeiro de 2009. Realizouse a semeadura de forma manual (auxílio de régua graduada) depositando-se duas sementes a cada $18,5 \mathrm{~cm}$, totalizando 54 sementes em cada linha de $5 \mathrm{~m}$.

Tabela 1. Condições climáticas durante o plantio e desenvolvimento dos híbridos de milho.

\begin{tabular}{|c|c|c|c|c|c|}
\hline Mês & TMA $\left({ }^{\circ} \mathrm{C}\right)^{1}$ & TMI $\left({ }^{\circ} \mathrm{C}\right)^{1}$ & T média $\left({ }^{\circ} \mathrm{C}\right)^{1}$ & UR $(\%)^{1}$ & Precipitação $(\mathrm{mm})$ \\
\hline & \multicolumn{5}{|c|}{2008} \\
\hline Setembro & 30,2 & 14,9 & 21,8 & 59,6 & 15,1 \\
\hline Outubro & 31,6 & 19,2 & 24,6 & 68,3 & 60,5 \\
\hline Novembro & 32,1 & 18,8 & 24,3 & 71,4 & 81,8 \\
\hline \multirow[t]{2}{*}{ Dezembro } & 31,0 & 19,1 & 23,9 & 77,0 & 278,9 \\
\hline & \multicolumn{5}{|c|}{2009} \\
\hline Janeiro & 29,7 & 19,8 & 23,8 & 80,4 & 238,0 \\
\hline Fevereiro & 31,2 & 20,6 & 24,7 & 80,9 & 190,6 \\
\hline Março & 31,0 & 20,2 & 24,4 & 80,4 & 217,9 \\
\hline Abril & 29,5 & 17,2 & 22,2 & 74,9 & 70,8 \\
\hline
\end{tabular}

${ }^{1} \mathrm{TMA}=$ temperatura máxima; $\mathrm{TMI}=$ temperatura mínima; $\mathrm{T}$ média $=$ temperatura média; $\mathrm{UR}=$ umidade relativa do ar.

Fonte: Elaboração dos autores.

Tabela 2. Análise química do solo ( 0 a $20 \mathrm{~cm}$ de profundidade) colhido na área experimental utilizada no plantio dos híbridos de milho.

\begin{tabular}{|c|c|c|c|c|c|c|c|c|c|}
\hline $\begin{array}{c}\mathbf{p H} \\
\mathrm{CaCl}_{2}\end{array}$ & $\begin{array}{c}\text { M.O. } \\
\left(\mathrm{g} / \mathbf{d m}^{3}\right)\end{array}$ & $\begin{array}{l}P(\text { resina }) \\
\left(\mathrm{mg} / \mathbf{d m}^{3}\right)\end{array}$ & $\mathbf{K}$ & $\mathbf{C a}$ & $\mathrm{Mg}$ & $\begin{array}{r}\mathbf{H}+\mathbf{A l} \\
\mathbf{m o l} / \mathbf{d m}^{3}\end{array}$ & SB & $\mathbf{T}$ & $\begin{array}{c}\mathrm{V} \\
(\%)\end{array}$ \\
\hline 4,8 & 18 & 18 & 1,8 & 17 & 11 & 38 & 29,8 & 67,8 & 44 \\
\hline
\end{tabular}

Fonte: Elaboração dos autores.

A parcela experimental foi composta por quatro linhas com $5 \mathrm{~m}$ de comprimento e espaçadas em $0,90 \mathrm{~m}$, abrangendo uma área total de $13,5 \mathrm{~m}^{2}$. Optou-se por utilizar 1,0 $\mathrm{m}$ de bordadura entre as linhas laterais, assim como no início e fim de cada linha da parcela. Portanto, a área útil das parcelas utilizadas no estudo correspondeu as duas linhas centrais com 3,0 m de comprimento cada. Entre blocos, respeitou-se 1,8 m de distância.

Decorridos 30 dias da semeadura, realizou-se a adubação de cobertura, sendo aplicados $100 \mathrm{~kg} \mathrm{ha}^{-1}$ de ureia ( $44 \%$ de $\mathrm{N}$ ) e desbaste de forma manual, permitindo o desenvolvimento de 27 plantas por linha. O controle de plantas daninhas foi realizado com a aplicação do herbicida Primestra Gold ${ }^{\mathbb{R}}$ na dosagem de $1 \mathrm{~L} \mathrm{ha}^{-1}$.

Os nove híbridos utilizados neste estudo foram caracterizados agronomicamente quanto à genética, ciclo cultural e finalidade de uso, índices estabelecidos pelo Zoneamento Agrícola de Risco Climático para ano safra 2007-2008 e 2008-2009 (Ministério da Agricultura, Pecuária e Abastecimento/MAPA) (Tabela 3).

As avaliações agronômicas foram realizadas na área útil de cada parcela experimental, determinando- 
se a produtividade de matéria verde $(P M V)$, produtividade de matéria seca $(P M S)$, população final de plantas por hectare $(P F)$, altura média das plantas $(H p)$, altura média de inserção de primeira espiga (Hesp), porcentagem de plantas acamadas e/ou quebradas $(P a q)$, lâminas foliares $(F O)$, colmos $(C O)$, palhas $(P A)$, espigas $(E S P)$ e relação folha:colmo $(F: C)$ das plantas de milho em razão dos diferentes híbridos utilizados. As determinações de $H p$ e Hesp ocorreram no campo uma semana antes do corte das plantas de milho, procedendo-se às medições de forma aleatória utilizando-se três plantas por parcela. A $H p$ compreendeu a altura da superfície do solo até a inserção da última folha e a Hesp foi medida desde a superfície do solo até a primeira espiga. $\mathrm{Na}$ avaliação da $P a q$ foi realizada a contagem das plantas acamadas e/ou quebradas por metro na área útil de cada parcela.

Tabela 3. Características agronômicas dos híbridos avaliados neste estudo.

\begin{tabular}{lllll}
\hline \multicolumn{1}{c}{ Empresa } & \multicolumn{1}{c}{ Híbridos } & \multicolumn{1}{c}{ Genética } & \multicolumn{1}{c}{ Ciclo } & \multicolumn{1}{c}{ Uso $^{*}$} \\
\hline Semília $^{1}$ & MX 300 & Híbrido triplo & Precoce & GR, SG e SP \\
MONSANTO $^{2}$ & RB 9308 & Híbrido triplo & Precoce & GR e SG \\
DOW $^{3}$ & 2B655 & Híbrido triplo & Precoce & GR e SP \\
SEMEALI $^{4}$ & XB 6012 & Híbrido simples & Precoce & GR \\
GENEZE $^{5}$ & GNZ 2500 & Híbrido simples & Precoce & GR, SG e SP \\
PLANAGRI $^{6}$ & PL6890 & Híbrido triplo & Precoce & GR, SG, SP e MV \\
GENESEEDS $^{7}$ & PRE 32D10 & Híbrido duplo & Precoce & GR, SG e SP \\
Prezotto $^{8}$ & PRE 22T10 & Híbrido triplo & Super-precoce & GR, SG e SP \\
MONSANTO $^{2}$ & AG 1051 & Híbrido duplo & Normal/tardio & GR \\
\hline
\end{tabular}

${ }^{1}$ Semília Genética e Melhoramento Ltda; ${ }^{2}$ Monsanto do Brasil Ltda; ${ }^{3}$ Dow Agrosciences; ${ }^{4}$ Semeali Sementes Híbridas Ltda; ${ }^{5} \mathrm{Geneze}$ Sementes Ltda; ${ }^{6}$ Planagri S/A; ${ }^{7}$ Geneseeds; ${ }^{8}$ Sementes Prezzotto Ltda. ${ }^{*} \mathrm{GR}=$ grão; SG = silagem de grão úmido; SP = silagem de planta inteira (picada); MV = milho verde.

Fonte: Elaboração dos autores.

As variáveis $P M V, P M S, P F, F O, C O, P A, E S P$ e relação $F: C$ foram determinadas após a colheita de cinco plantas da área útil de cada parcela (cortadas manualmente a $10 \mathrm{~cm}$ da superfície do solo), pesando-se os componentes separados em lâminas foliares, colmos + bainhas, espigas e palhas. Após a separação, uma amostra representativa de cada componente foi pesada e levada à estufa de circulação forçada de ar a $55^{\circ} \mathrm{C}$ por 72 horas para determinação do teor de matéria seca (MS). As amostras de lâminas foliares e colmos + bainhas foram moídas em peneira de malha com crivos de 1,0 mm em moinho tipo "Willye" para posteriores análises bromatológicas.

Decorridos 101 dias da semeadura, quando a linha do leite no grão da maioria dos híbridos estava entre $1 / 3$ e $2 / 3$ (28 a 33\% de MS), 10 plantas da área útil $\left(2,70 \mathrm{~m}^{2}\right)$ de cada parcela foram cortadas manualmente a $10 \mathrm{~cm}$ do nível do solo. As plantas foram picadas em picadeira estacionária regulada para cortes das partículas em 2,0 cm. Posteriormente, realizou-se a homogeneização retirando-se amostras representativas de cada parcela para determinação das variáveis químico-bromatológicas.

As avaliações das características químicas dos híbridos de milho foram realizadas em extrato aquoso (KUNG JÚNIOR et al., 1984), sendo determinados o potencial hidrogeniônico $(\mathrm{pH})$, teores de nitrogênio amoniacal em relação ao nitrogênio total $\left(\mathrm{N}-\mathrm{NH}_{3} \mathrm{NT}^{-1}\right)$ e capacidade tampão (CT) em mEq de $\mathrm{NaOH}$ por $100 \mathrm{~g}$ de MS. A capacidade tampão foi determinada pelo método de Playne e McDonald (1966) e os teores de $\mathrm{N}_{-} \mathrm{NH}_{3}$ $\mathrm{NT}^{-1}$ foram obtidos por destilação com hidróxido de potássio $2 \mathrm{~N}$ conforme (VIEIRA, 1980). 
Os teores de MS, cinzas (CZ), nitrogênio total (NT) e extrato etéreo (EE) foram determinados conforme Silva e Queiroz (2002), sendo a proteína bruta (PB) obtida pelo produto entre o NT e o fator 6,25. Os teores de fibra em detergente neutro (FDN) e fibra em detergente ácido (FDA) foram avaliados segundo as técnicas descritas por Van Soest, Robertson e Lewis (1991). A lignina (LIG) foi determinada após a solubilização da celulose (CEL) em ácido sulfúrico a 72\% (VAN SOEST, 1994). O nitrogênio insolúvel em detergente neutro (NIDN) e ácido (NIDA) foi determinado seguindo o protocolo apresentado por Licitra, Hernandez e Van Soest (1996).

O experimento foi conduzido em blocos casualizados (DBC) avaliando-se nove híbridos de milho, com três repetições por tratamento. Os dados foram submetidos à análise de variância e as médias dos tratamentos comparadas pelo Teste SNK (Student-Newman-Keuls) a $5 \%$ de probabilidade por meio do software SAS (SAS v. 9.0, 2002).

\section{Resultados e Discussão}

As maiores produções de MV foram verificadas nos híbridos PL 6890 (40,84 t ha-1) e PRE 32D10 (42,53 $\left.\mathrm{t} \mathrm{ha}^{-1}\right)$, seguidos dos RB $9308\left(39,11 \mathrm{t} \mathrm{ha}^{-1}\right)$, XB $6012\left(38,51 \mathrm{t} \mathrm{ha}^{-1}\right)$, GNZ $2500\left(37,79 \mathrm{t} \mathrm{ha}^{-1}\right) \mathrm{e}$ AG $1051\left(38,25 \mathrm{t} \mathrm{ha}^{-1}\right)$. A maior produção de MS foi observada no híbrido PRE 32D10 (13,43 tha-1). A produção de MS é um dos primeiros parâmetros a ser avaliado, antecedendo aos parâmetros de qualidade, uma vez que contribui para diminuir os custos de implantação da cultura por elevar a produtividade, além de ser um parâmetro para o dimensionamento de silos (PAZIANI et al., 2009). A produção verificada no híbrido PRE 32D10 está próxima à média reportada por Zopollatto et al. (2009), cujos autores verificaram produção de MS de 15,1 t ha-1 trabalhando com os híbridos de milho CO 32, AG 5011, P 3041, DKB 333B, AG 1051 e Z 8550 colhidos com aproximadamente 102 dias após semeadura. Entretanto, as produções verificadas neste estudo estão aquém do potencial observado em outros híbridos (RABÊLO et al., 2013).

A menor população final (PF) de plantas entre os híbridos estudados foi verificada no PL 6890 (49.835 plantas $\left.\mathrm{ha}^{-1}\right)$. Embora não tenha sido avaliada a qualidade das sementes, bem como a porcentagem de germinação, é provável que a emergência de plântulas foi baixa em relação ao híbrido PL 6890, o que proporcionou menor estande comparado aos demais híbridos. Nos demais híbridos a PF ficou acima de 60.000 plantas por hectare. Embora o híbrido PRE 32D10 tenha apresentado a maior produtividade, o mesmo não ocorreu na população final de plantas (PF). De maneira geral, notouse que maiores populações de plantas resultaram em menor produção de MS, o que pode estar correlacionado à competição por nutrientes no solo e energia solar para realização da fotossíntese, implicando em menor desenvolvimento das plantas (Tabela 4). Segundo recomendação técnica da EPAMIG (Empresa de Pesquisa Agropecuária de Minas Gerais), quando o plantio é realizado com espaçamento entre linhas de $0,90 \mathrm{~m}$, como no caso do presente estudo, a população final desejada deve estar acima de 60.000 plantas/ha, o que não foi verificado apenas no híbrido PL6890, embora tenha apresentado uma das maiores produção de $\mathrm{MV}$ (40,84 t MV ha' $\left.{ }^{-1}\right)$ e MS (12,20 t MS ha-1).

Quanto à altura de plantas, o híbrido AG 1051 foi o maior com $1,88 \mathrm{~m}$, enquanto o XB 6012 foi o menor com 1,63 m, caracterizando-se como materiais de porte baixo (menor que 2,00 m) segundo Jaremtchuk et al. (2005). O híbrido tardio AG 1051 também se destacou pela maior altura de inserção de espiga (1,06 m). Estes resultados estão de acordo com Flaresso, Gross e Almeida (2000), que observaram maior altura de plantas nos híbridos de milho mais tardios, em relação aos mais precoces.

Houve maior acamamento ou quebra de plantas nos híbridos RB 9308 (12,73\%) e XB 6012 (14,13\%) (Tabela 4). Dourado Neto et al. (2003) destaca que a maior população de plantas por área pode implicar 
em maior acamamento e quebra de plantas. Tal fato pode ser considerado ao híbrido RB 9308, que apresentou uma das maiores populações final de plantas por hectare (67.114) e também uma das maiores altura de planta $(1,78 \mathrm{~m})$. Por outro lado, o híbrido XB 6012 apresentou população final de plantas por hectare, intermediária (63.000 plantas $\left.\mathrm{ha}^{-1}\right)$ e menor altura $(1,63 \mathrm{~m})$. Segundo Jaremtchuk et al. (2005) plantas de porte baixo poderiam reduzir as perdas por acamamento e quebramento, contudo tal inferência não foi verificada na presente pesquisa. Neste caso, observou-se que os valores dos constituintes da fração fibrosa do colmo + bainha deste híbrido foram menores comparado aos demais (Tabela 4). Outro fator importante sobre esta variável refere-se na maior dificuldade de colheita em áreas com maior número de plantas acamadas e/ou quebradas, resultando em maior tempo e custo de colheita.

Tabela 4. Características agronômicas dos híbridos de milho após 101 dias de semeadura ${ }^{1}$.

\begin{tabular}{lllllll}
\hline \multicolumn{1}{c}{ Híbridos* } & PMV & PMS & PF & Hp & Hesp & Paq \\
\hline MX 300 & $33,47 \mathrm{~d}$ & $12,37 \mathrm{~b}$ & $61.741 \mathrm{c}$ & $1,83 \mathrm{ab}$ & $0,89 \mathrm{~b}$ & $4,41 \mathrm{bc}$ \\
RB 9308 & $39,11 \mathrm{ab}$ & $11,33 \mathrm{~cd}$ & $67.114 \mathrm{a}$ & $1,78 \mathrm{abc}$ & $0,88 \mathrm{~b}$ & $12,73 \mathrm{a}$ \\
2B655 & $34,27 \mathrm{~cd}$ & $10,65 \mathrm{~d}$ & $66.537 \mathrm{a}$ & $1,71 \mathrm{abc}$ & $0,93 \mathrm{~b}$ & $2,22 \mathrm{c}$ \\
XB 6012 & $38,51 \mathrm{abc}$ & $11,71 \mathrm{cb}$ & $63.000 \mathrm{bc}$ & $1,63 \mathrm{c}$ & $0,86 \mathrm{~b}$ & $14,13 \mathrm{a}$ \\
GNZ 2500 & $37,79 \mathrm{abc}$ & $11,08 \mathrm{~cd}$ & $65.306 \mathrm{ab}$ & $1,73 \mathrm{abc}$ & $0,89 \mathrm{~b}$ & $6,62 \mathrm{~b}$ \\
PL6890 & $40,84 \mathrm{a}$ & $12,20 \mathrm{~b}$ & $49.835 \mathrm{~d}$ & $1,84 \mathrm{ab}$ & $0,89 \mathrm{~b}$ & $5.80 \mathrm{~b}$ \\
PRE 32D10 & $42,53 \mathrm{a}$ & $13,43 \mathrm{a}$ & $62.835 \mathrm{bc}$ & $1,68 \mathrm{bc}$ & $0,84 \mathrm{~b}$ & $4,20 \mathrm{bc}$ \\
PRE 22T10 & $35,48 \mathrm{bcd}$ & $10,97 \mathrm{~cd}$ & $66.863 \mathrm{a}$ & $1,66 \mathrm{bc}$ & $0,78 \mathrm{~b}$ & $5,63 \mathrm{~b}$ \\
AG 1051 & $38,25 \mathrm{abc}$ & $11,04 \mathrm{~cd}$ & $60.795 \mathrm{c}$ & $1,88 \mathrm{a}$ & $1,06 \mathrm{a}$ & $4,70 \mathrm{bc}$ \\
\hline Valor de P & 0,0002 & $<0,0001$ & $<0,0001$ & 0,0034 & 0,0028 & $<0,0001$ \\
\hline CV (\%) & 4,82 & 2,99 & 2.06 & 3,88 & 6,62 & 18,70 \\
\hline
\end{tabular}

*Médias seguidas de mesma letra, na coluna, não diferem pelo Teste SNK $(\mathrm{P}>0,05)$.

${ }^{1} \mathrm{PMV}=$ produtividade de matéria verde $(\mathrm{t} / \mathrm{ha}) ; \mathrm{PMS}=$ produtividade de matéria seca $(\mathrm{t} / \mathrm{ha}) ; \mathrm{PF}=$ população final; Hp = altura média das plantas (m); Hesp = altura média de inserção da primeira espiga (m); Paq = plantas acamadas e quebradas $(\%)$.

Fonte: Elaboração dos autores.

Segundo Zopolatto et al. (2009), a composição estrutural da planta tem influencia direta sobre sua qualidade, assim como a variação nestas frações, devido aos fatores genotípicos e fenotípicos, tem consequências sobre a produção e a composição química do híbrido. Desta forma, para produzir silagem de milho de qualidade, além da quantidade de grãs na massa ensilada e a elevada produtividade, a proporção de outras frações da planta e digestibilidade também são fatores muito importantes a serem considerados (ZOPOLATTO et al., 2009).

Os híbridos PRE 32D10 (7,31\%) e PRE 22T10 $(7,29 \%)$ se destacaram por apresentar maior porcentagem de lâminas foliares em relação à planta inteira, seguidos dos híbridos PL 6890 (6,51\%), GNZ 2500 (6,37\%), RB 9308 (6,36\%) e $A G 1051$ (5,64\%). Enquanto que a menor porcentagem de colmos foi observada nos híbridos MX 300 (11,69\%), 2B655 (11,32\%) e XB 6012 $(11,14 \%)$. Entretanto a maior relação folha:colmo foi observada no híbrido XB $6012(0,49)$ e a menor no híbrido MX300 (0,38), ficando os demais com valores intermediários (Tabela 5).

As porcentagens de palha variaram de 10,73\% (2B655) a 17,45\% (XB 6012) nos híbridos. A variação na porcentagem de palha verificada neste trabalho está próxima à encontrada por Jaremtchuk et al. (2005), cujos autores estudaram 20 genótipos de milho e verificaram valores entre 
10,2 e $15,8 \%$. Vale salientar que a proteção da palha à espiga é importante contra o ataque de insetos. A maior participação de espigas foi encontrada nos híbridos 2B655 (71,15\%) e PL6890 (72,82\%), enquanto o híbrido AG 1051 apresentou menor porcentagem (62,44\%). Nussio (1992) preconiza que a participação de espigas na planta destinada à ensilagem deve estar próxima a $65 \%$, no intuito de garantir a qualidade do material.
Estes resultados são interessantes do ponto de vista qualitativo, visto que maiores porcentagens de espigas implicam em maior conteúdo de amido advindo dos grãos, enquanto maiores relações folha:colmo podem resultar em maior conteúdo de proteína e carboidratos solúveis. Assim, temse que os carboidratos solúveis da planta afetam a qualidade da silagem, influenciando diretamente o processo de fermentação, enquanto o conjunto de carboidratos estruturais e não-estruturais tem marcada influência no processo digestivo do animal (REIS; JOBIM, 2000).

Tabela 5. Porcentagens de laminas foliares (FO), colmo (CO), palha (PA), espigas (ESP), material morto (MM) e relação folha:colmo (F:C) dos híbridos de milho.

\begin{tabular}{lllllll}
\hline \multicolumn{1}{c}{ Híbridos* } & FO & CO & PA & ESP & MM & F:C \\
\hline MX 300 & $4,95 \mathrm{~b}$ & $11,69 \mathrm{c}$ & $15,31 \mathrm{a}$ & $67,00 \mathrm{bc}$ & $0,79 \mathrm{a}$ & $0,38 \mathrm{~b}$ \\
RB 9308 & $6,36 \mathrm{ab}$ & $15,37 \mathrm{a}$ & $14,59 \mathrm{a}$ & $63,46 \mathrm{~cd}$ & $0,31 \mathrm{bc}$ & $0,41 \mathrm{ab}$ \\
2B655 & $5,28 \mathrm{~b}$ & $11,32 \mathrm{c}$ & $10,73 \mathrm{~b}$ & $71,15 \mathrm{a}$ & $0,13 \mathrm{c}$ & $0,42 \mathrm{ab}$ \\
XB 6012 & $5,35 \mathrm{~b}$ & $11,14 \mathrm{c}$ & $17,45 \mathrm{a}$ & $63,70 \mathrm{~cd}$ & $0,73 \mathrm{a}$ & $0,49 \mathrm{a}$ \\
GNZ 2500 & $6,37 \mathrm{ab}$ & $13,87 \mathrm{ab}$ & $11,86 \mathrm{~b}$ & $67,69 \mathrm{~b}$ & $0,21 \mathrm{bc}$ & $0,46 \mathrm{ab}$ \\
PL6890 & $6,51 \mathrm{ab}$ & $15,41 \mathrm{a}$ & $15,02 \mathrm{a}$ & $72,82 \mathrm{a}$ & $0,75 \mathrm{a}$ & $0,43 \mathrm{ab}$ \\
PRE 32D10 & $7,31 \mathrm{a}$ & $14,65 \mathrm{ab}$ & $14,54 \mathrm{a}$ & $64,93 \mathrm{bcd}$ & $0,49 \mathrm{ab}$ & $0,47 \mathrm{ab}$ \\
PRE 22T10 & $7,29 \mathrm{a}$ & $15,79 \mathrm{a}$ & $11,35 \mathrm{~b}$ & $66,04 \mathrm{bcd}$ & $0,67 \mathrm{a}$ & $0,46 \mathrm{ab}$ \\
AG 1051 & $5,64 \mathrm{ab}$ & $12,69 \mathrm{bc}$ & $16,10 \mathrm{a}$ & $62,44 \mathrm{~d}$ & $0,70 \mathrm{a}$ & $0,44 \mathrm{ab}$ \\
\hline Valor de P & 0,0031 & $<0,0001$ & $<0,0001$ & $<0,0001$ & $<0,0001$ & 0,0413 \\
\hline CV (\%) & 10,94 & 7,48 & 8,31 & 2,17 & 25,00 & 7,78 \\
\hline
\end{tabular}

${ }^{*}$ Médias seguidas de mesma letra, na coluna, não diferem pelo Teste SNK $(\mathrm{P}>0,05)$.

Fonte: Elaboração dos autores.

O híbrido MX 300 apresentou o maior teor de MS (33,78\%). Embora os híbridos de ciclos vegetativos diferentes tenham sido colhidos na mesma data (aos 101 dias), estes apresentaram desenvolvimento semelhante, verificado pela proximidade da linha de leite, porém diferentes teores de MS (variação de 28 a 33\%) foram encontrados, até mesmo entre os híbridos de ciclo precoce (Tabela 6). Nussio (1991) recomenda que o teor de MS das plantas de milho utilizadas no processo de ensilagem deve estar entre 30 e 37\%. Desta forma, os híbridos RB 9308 (28,96\%), PL6890 (29,90\%) e AG 1051 (28,88\%) ficaram abaixo desta faixa, o que pode implicar em maiores perdas de MS devido principalmente a produção de efluentes em virtude da maior umidade nestas plantas. Ressalta-se que períodos maiores após a semeadura do milho seriam necessários para estes híbridos atingirem o teor de MS ideal para colheita. Outro fator refere-se à fermentação indesejável que pode ocorrer em silagens com baixo teor de MS pela proliferação de microrganismos indesejáveis, como o Clostridium (MCDONALD; HENDERSON; HERON, 1991). 
Tabela 6. Composição bromatológica (\% na MS) das plantas de milho dos híbridos avaliados ${ }^{1}$

\begin{tabular}{lllllllllll}
\hline \multicolumn{1}{c}{ Híbridos* } & MS & CZ & PB & FDN & FDA & LIG & HEM & CEL & NIDN & NIDA \\
\hline MX 300 & $33,78 \mathrm{a}$ & 4,46 & $8,78 \mathrm{ab}$ & $63,04 \mathrm{c}$ & $36,49 \mathrm{ab}$ & $6,32 \mathrm{~b}$ & $30,74 \mathrm{ab}$ & 26,96 & $31,78 \mathrm{~b}$ & $28,71 \mathrm{a}$ \\
RB 9308 & $28,96 \mathrm{~d}$ & 4,02 & $8,14 \mathrm{c}$ & $64,85 \mathrm{~b}$ & $34,20 \mathrm{~b}$ & $6,98 \mathrm{~b}$ & $28,52 \mathrm{ab}$ & 27,23 & $27,91 \mathrm{c}$ & $24,09 \mathrm{abc}$ \\
2B655 & $31,10 \mathrm{bc}$ & 4,04 & $8,34 \mathrm{c}$ & $66,54 \mathrm{a}$ & $32,30 \mathrm{~b}$ & $6,53 \mathrm{~b}$ & $34,62 \mathrm{a}$ & 25,78 & $30,57 \mathrm{~b}$ & $22,44 \mathrm{c}$ \\
XB 6012 & $30,41 \mathrm{bc}$ & 4,03 & $9,00 \mathrm{a}$ & $59,57 \mathrm{~d}$ & $34,37 \mathrm{~b}$ & $6,82 \mathrm{~b}$ & $26,82 \mathrm{ab}$ & 27,54 & $33,51 \mathrm{~b}$ & $27,71 \mathrm{ab}$ \\
GNZ 2500 & $30,56 \mathrm{bc}$ & 4,35 & $8,06 \mathrm{c}$ & $57,78 \mathrm{e}$ & $33,03 \mathrm{~b}$ & $6,27 \mathrm{~b}$ & $27,16 \mathrm{ab}$ & 24,27 & $38,35 \mathrm{a}$ & $25,94 \mathrm{abc}$ \\
PL6890 & $29,90 \mathrm{~cd}$ & 4,18 & $8,81 \mathrm{ab}$ & $65,18 \mathrm{~b}$ & $39,20 \mathrm{a}$ & $8,63 \mathrm{a}$ & $27,92 \mathrm{ab}$ & 29,56 & $32,33 \mathrm{~b}$ & $25,34 \mathrm{abc}$ \\
PRE 32D10 & $31,58 \mathrm{~b}$ & 4,53 & $9,10 \mathrm{a}$ & $64,72 \mathrm{~b}$ & $35,46 \mathrm{~b}$ & $6,92 \mathrm{~b}$ & $29,46 \mathrm{ab}$ & 29,16 & $33,18 \mathrm{~b}$ & $28,17 \mathrm{a}$ \\
PRE 22T10 & $30,91 \mathrm{bc}$ & 4,62 & $8,50 \mathrm{bc}$ & $64,51 \mathrm{~b}$ & $34,11 \mathrm{~b}$ & $7,50 \mathrm{ab}$ & $27,24 \mathrm{ab}$ & 31,33 & $36,94 \mathrm{a}$ & $28,17 \mathrm{a}$ \\
AG 1051 & $28,88 \mathrm{~d}$ & 4,330 & $9,01 \mathrm{a}$ & $63,35 \mathrm{c}$ & $36,16 \mathrm{ab}$ & $7,63 \mathrm{ab}$ & $25,19 \mathrm{~b}$ & 24,33 & $32,39 \mathrm{~b}$ & $23,32 \mathrm{bc}$ \\
\hline Valor de P & $<0,0001$ & 0,4949 & $<0,0001$ & $<0,0001$ & 0,0016 & 0,0092 & 0,0415 & $<0,0001$ & $<0,0001$ & 0,0023 \\
\hline CV (\%) & 1,60 & 8,44 & 2,28 & 0,86 & 5,66 & 9,25 & 10,08 & 3,39 & 3,52 & 6,76 \\
\hline
\end{tabular}

*Médias seguidas de mesma letra, na coluna, não diferem pelo Teste SNK ( $\mathrm{P}>0,05)$.

${ }^{1} \mathrm{MS}=$ matéria seca; $\mathrm{CZ}$ = cinzas; $\mathrm{PB}=$ proteína bruta; $\mathrm{FDN}$ = fibra em detergente neutro; FDA = fibra em detergente ácido; LIG = lignina; $\mathrm{HEM}=$ hemicelulose; $\mathrm{CEL}=$ celulose; $\mathrm{NIDN}=$ nitrogênio insolúvel em detergente neutro; NIDA = nitrogênio insolúvel em detergente ácido.

Fonte: Elaboração dos autores.

Com relação ao teor de $\mathrm{PB}$ da planta de milho (Tabela 6), os híbridos XB 6012 (9,00\% da MS), PRE 32D10 (9,10\% da MS) e AG $1051(9,01 \%$ da MS) apresentaram maiores teores, seguidos dos híbridos MX 300 (8,78\% da MS) e PL 6890 (8,81\% da MS). As diferenças observadas quanto ao teor de $\mathrm{PB}$ podem estar relacionadas a diferenças na eficiência de absorção do $\mathrm{N}$ disponível no solo para a planta, em que os diversos híbridos e variedades requerem quantidades diferentes de $\mathrm{N}$, de acordo com seu potencial de produtividade (FERNANDES et al., 2005). Os teores de PB encontrados no presente estudo estão de acordo com outros achados em diferentes regiões do país (PINTO et al., 2010).

O maior teor de FDN foi encontrado no híbrido 2B655 (66,54\% da MS) e o menor no GNZ 2500 $(57,78 \%$ da MS). Embora não tenham sido realizados cortes histológicos neste estudo, sabe-se que no colmo destes híbridos há células de menor ou maior tamanho individual, resultante de programas de melhoramento genético para aumentar a resistência do colmo ao acamamento e agentes patógenos (NUSSIO, 1991) e, que isto pode implicar em diferentes concentrações de fibra na planta.

O estudo da fração fibrosa é de suma importância na avaliação da qualidade dos híbridos para o processo de ensilagem, pois como se sabe, o teor de FDN é correlacionado inversamente com o consumo e digestibilidade do alimento quando ingerido pelo animal (VAN SOEST, 1994). Além disso, a concentração de fibra pode estar inversamente correlacionada com a concentração de açúcares livres na planta (influenciados pelo estádio de maturidade e mecanismos de translocação de nutrientes para a sustentação das plantas), os quais são os principais substratos para a fermentação realizada pelas bactérias ácido-láticas. Adicionalmente, estas bactérias não possuem a capacidade de degradar e/ou utilizar fibra dentro do silo (MCDONALD; HENDERSON; HERON, 1991). Portanto, caso a produção de MS não seja comprometida, assim como o acamamento de plantas (o que dificultaria a colheita), híbridos com menores teores de fibra devem ser escolhidos para o processo de ensilagem.

O híbrido PL6890 apresentou maior teor de FDA (39,20\% da MS) e lignina ( $8,63 \%$ da MS). O híbrido PRE 32D10 apresentou maiores teores na fração celulose $(31,33 \%$ da $\mathrm{MS})$, no $\mathrm{N}$ retido na FDN (NIDN) $(36,94 \%$ da PB) e $\mathrm{N}$ retido na FDA (NIDA) $(28,17 \%$ da PB). Segundo Van Soest (1994), o NIDA representa a fração do $\mathrm{N}$ que está indisponível ao animal (associado à lignina), 
pois suas características o tornam indigestível durante o trânsito no trato gastrintestinal. A maior porcentagem de fibra é indesejável, visto que esta entidade está correlacionada negativamente com o consumo de nutrientes pelos animais.

As características químicas dos híbridos estão apresentadas na Tabela 7. A planta de milho do híbrido MX 300 apresentou maior valor de $\mathrm{pH}$ $(6,49)$, enquanto o menor valor foi encontrado no híbrido AG 1051 (6,25), os valores do $\mathrm{pH}$ das demais plantas de milho dos híbridos estudados permaneceram entre estes. Embora a análise dos valores de $\mathrm{pH}$ não sejam essenciais para a escolha de um híbrido a ser utilizado no processo de ensilagem, esta variável está associada principalmente com a concentração de proteína e minerais na planta, o que pode indiretamente contribuir para o entendimento de como a planta aloca $\mathrm{N}$ e minerais presentes no solo. Contudo a maior capacidade tampão (CT) foi verificada no híbrido PL6890 (0,77), seguido dos híbridos GNZ $2500\left(0,57 \mathrm{mEq} 100 \mathrm{~g}^{-1}\right)$, PRE 32D10 $\left(0,54 \mathrm{mEq} 100 \mathrm{~g}^{-1}\right), \mathrm{AG} 1051\left(0,53 \mathrm{mEq} 100 \mathrm{~g}^{-1}\right), \mathrm{RB}$ $9308\left(0,53 \mathrm{mEq} 100 \mathrm{~g}^{-1}\right)$ e MX $300\left(0,50 \mathrm{mEq} 100 \mathrm{~g}^{-}\right.$ $\left.{ }^{1}\right)$. O híbrido $2 \mathrm{~B} 655$ foi o que apresentou menor $\mathrm{CT}$ $\left(0,29 \mathrm{mEq} 100 \mathrm{~g}^{-1}\right)$, mas sem diferença significativa comparado ao XB $6012\left(0,48 \mathrm{mEq} 100 \mathrm{~g}^{-1}\right)$ e PRE $22 \mathrm{~T} 10\left(0,45 \mathrm{mEq} 100 \mathrm{~g}^{-1}\right)$. O conhecimento da CT da forragem a ser utilizada é um fator importante, pois fornece informações em relação à alteração do pH (JOBIM et al., 2007), sendo que em casos onde a CT é alta, a queda do $\mathrm{pH}$ ocorre de forma mais lenta resultando em maiores perdas durante o processo de ensilagem, o que implica em menor qualidade da silagem produzida (CHERNEY; CHERNEY, 2003).

O híbrido 2B655 apresentou maior teor de $\mathrm{N}_{-} \mathrm{NH}_{3}(4,53 \%$ NT). Assim como o teor de PB reflete a eficiência de utilização do $\mathrm{N}$ disponível no solo para a planta (FERNANDES et al., 2005), o teor de $\mathrm{N}-\mathrm{NH}_{3}$ reflete em qual fração a planta é mais eficiente em aloca-lo. Neste sentido, sabe-se que o
N-NH 3 compõe a fração A da proteína (LICITRA; HERNANDEZ; VAN SOEST, 1996), o qual é mais disponível do que as demais frações aos animais. Portanto, caso esta fração não seja utilizada por microrganismos presentes na silagem, o maior teor de $\mathrm{N}-\mathrm{NH}_{3}$ supre uma fonte de rápida degradação aos microrganismos do rúmen. Contudo, vale ressaltar que a silagem tem por função contribuir com aporte energético e não protéico na nutrição animal.

Quanto à composição bromatológica das lâminas foliares (Tabela 8), os híbridos RB 9308 (28,93\%) e PL6890 (32,27\%) apresentaram maior teor de MS, seguidos dos híbridos PRE 32D10 (30,68\%), GNZ 2500 (30,11\%) e MX 300 (30,14\%). O híbrido GNZ 2500 se destacou pelo maior teor de cinzas (7,69\%). Os maiores teores de PB foram verificados nas lâminas foliares dos híbridos XB 6012 (17,36\% da MS) e GNZ 2500 (17,88\% da MS).

O maior teor de FDN nas lâminas foliares foi verificado no híbrido AG 1051 (65,38\% da MS). O mesmo híbrido apresentou menores teores de lignina $(4,20 \%$ da MS) e NIDN $(35,68 \%$ da PB) e maior teor de hemicelulose $(29,94 \%$ da MS). Os teores de FDN encontrados nas laminas foliares dos híbridos estudados na presente pesquisa ficaram abaixo dos valores observados por Zeoula et al. (2003), cujos autores reportaram variação de 65,07 a 70,64\% na lâmina foliar de cinco híbridos de milho (P32R21, P30R07, P3041, P30F33 e P30F80). O híbrido PRE 32D10 (35,53\% da MS) e RB 9308 (35,43\% da MS) apresentaram maiores teores de FDA nas folhas, seguidos dos híbridos 2B655 (34,56\% da MS) e GNZ 2500 (34,53\% da MS). O maior conteúdo de celulose foi verificado no híbrido MX 300 (31,11\% da MS). Por outro lado, os híbridos 2B655 (27,71\% da MS) e PRE $22 \mathrm{~T} 10$ $(28,06 \%$ da MS) apresentaram os menores teores de celulose. A menor concentração de $\mathrm{N}$ retido no FDA foi encontrada no híbrido PL6890 (9,50\% da PB) (Tabela 8). 
Tabela 7. Valores de pH, capacidade tampão (CT) e nitrogênio amoniacal em relação ao nitrogênio total $\left(\mathrm{N}_{-} \mathrm{NH}_{3} / \mathrm{NT}\right)$ nas plantas de milho.

\begin{tabular}{llll}
\hline Híbridos* & pH & C T (mEq/100 g) & N-NH $\mathbf{~}(\mathbf{\%} \mathbf{~ N})$ \\
\hline MX 300 & $6,49 \mathrm{a}$ & $0,50 \mathrm{ab}$ & $2,10 \mathrm{c}$ \\
RB 9308 & $6,37 \mathrm{ab}$ & $0,53 \mathrm{ab}$ & $3,87 \mathrm{ab}$ \\
2B655 & $6,43 \mathrm{ab}$ & $0,29 \mathrm{~b}$ & $4,53 \mathrm{a}$ \\
XB 6012 & $6,45 \mathrm{ab}$ & $0,48 \mathrm{~b}$ & $3,09 \mathrm{abc}$ \\
GNZ 2500 & $6,33 \mathrm{ab}$ & $0,57 \mathrm{ab}$ & $2,87 \mathrm{bc}$ \\
PL6890 & $6,38 \mathrm{ab}$ & $0,77 \mathrm{a}$ & $3,67 \mathrm{ab}$ \\
PRE 32D10 & $6,37 \mathrm{ab}$ & $0,54 \mathrm{ab}$ & $3,77 \mathrm{ab}$ \\
PRE 22T10 & $6,33 \mathrm{ab}$ & $0,45 \mathrm{~b}$ & $4,50 \mathrm{ab}$ \\
AG 1051 & $6,25 \mathrm{~b}$ & $0,53 \mathrm{ab}$ & $3,03 \mathrm{bc}$ \\
\hline Valor de P & 0,0356 & 0,0068 & 0,0014 \\
\hline CV (\%) & 1,19 & 20,30 & 16,29 \\
\hline
\end{tabular}

*Médias seguidas de mesma letra, na coluna, não diferem pelo Teste SNK $(\mathrm{P}>0,05)$.

Fonte: Elaboração dos autores.

A composição bromatológica do colmo + bainha dos híbridos está apresentada na Tabela 9. O maior teor de MS na fração colmo + bainha foi verificado no híbrido GNZ 2500 (27,03\%), seguido do híbrido XB 6012 (26,28\%). Os valores de MS observados neste trabalho estão abaixo aos observados por Zopollatto et al. (2009), que estudou diferentes frações da planta de seis híbridos de milho para ensilagem e reportou variação de 19,2 a 23,9\%, na fração colmo.

Os híbridos XB 6012 (4,14\% da MS), GNZ 2500 (4,11\% da MS) e PL6890 (4,09\% da MS) se destacaram pelo maior teor de PB na fração colmo + bainha em relação aos demais híbridos. Os teores mais elevados de FDN (74,23\% da MS) e NIDN (36,07\% da PB) foram verificados no híbrido PRE 32D10, enquanto o híbrido MX 300 se destacou pelos maiores teores de FDA $(50,40 \%$ da MS), lignina $(9,22 \%$ da $\mathrm{MS})$ e celulose $(41,22 \%$ da MS). A maior concentração de $\mathrm{N}$ retido no FDA do colmo + bainha foi encontrada no 2B655 (26,26\% da PB). Maiores teores de fibra nas frações colmo + bainha podem garantir menor porcentagem de plantas acamadas e/ou quebradas, tornando-se fatores interessantes na escolha dos híbridos. Por outro lado, elevados teores de fibra podem interferir negativamente na qualidade da silagem produzida e, consequentemente afetar o consumo de matéria seca pelos animais.

Embora haja diferenças na composição químicobromatológica dos híbridos de milho avaliados neste estudo, recomenda-se utilizar os híbridos MX 300, PL6890 e PRE 32D10 por apresentarem produção de matéria seca mais elevada, os quais podem refletir na amortização dos custos na produção das silagens. 


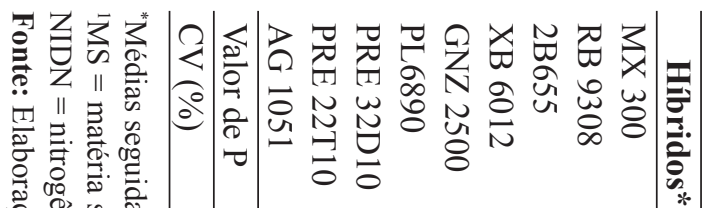

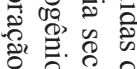

을

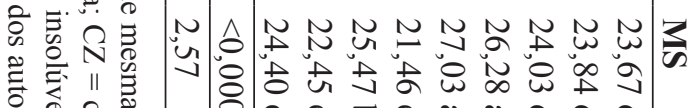

盆

월

可

曋

穵苛志

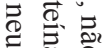

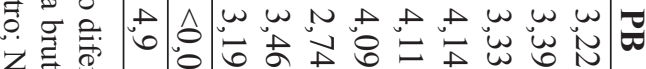

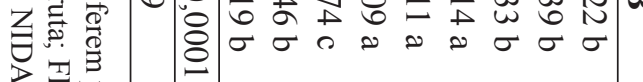

ㄹ.

官

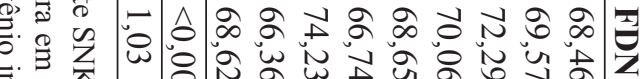

E.

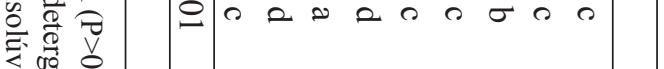

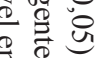

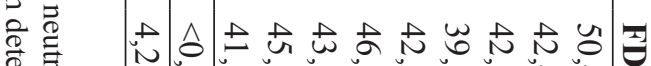

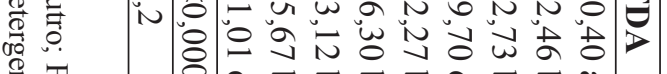

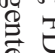

กิ.

气. ํ.

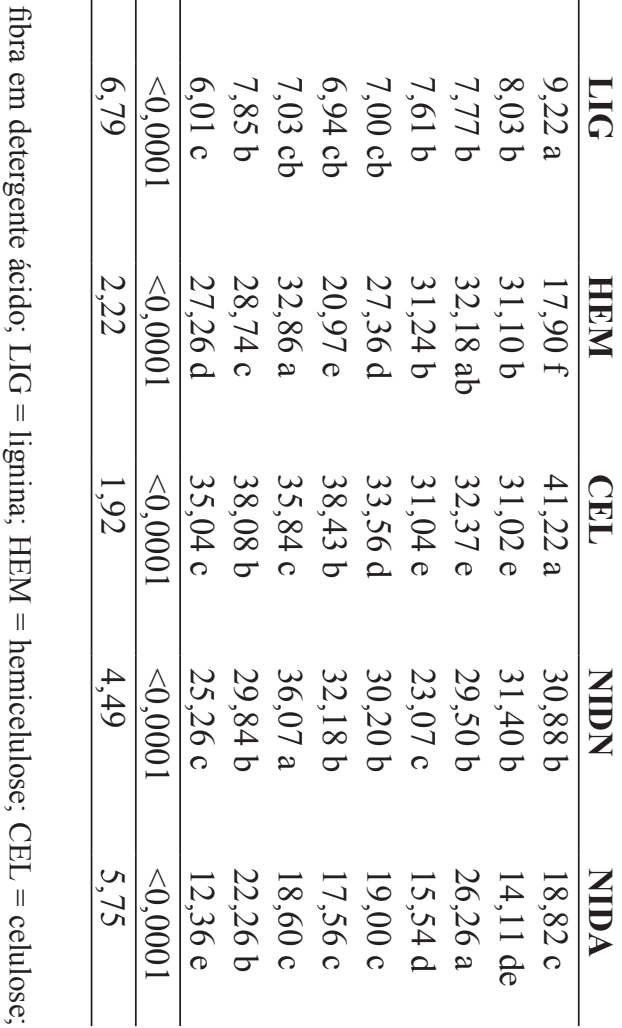

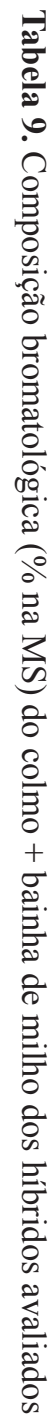

군

‥

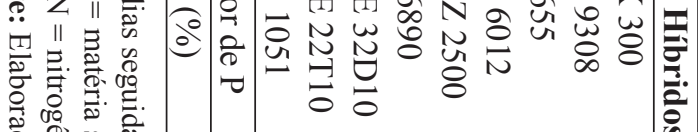

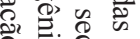

ค. ำ

施 $\Omega$

艺 $N$

$\stackrel{0}{0} \stackrel{0}{\circ}$

坣

की

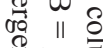

के 동

ह

○ें

늘

$\exists$ 苛

II Z

ㅋ.引ㅇ.

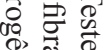

응. 当

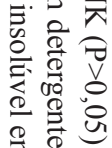

จे ซ

(⿻)

导

กิ.

ㅇํㅇ

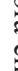

8

वृ

है.

듬

谷

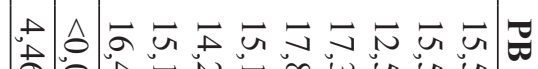

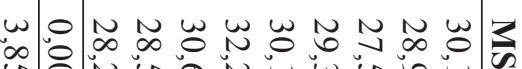

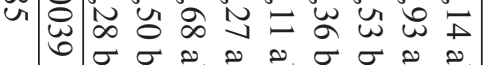

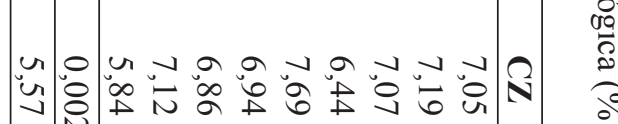

-

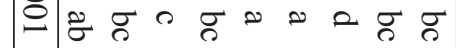

vio

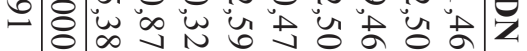

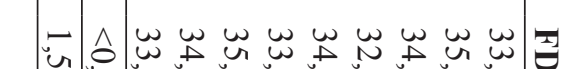

u

ठㅁ

a $\wedge \rightarrow$ a un a v $v \rightarrow$ un $\rightarrow$ ?

w

๖

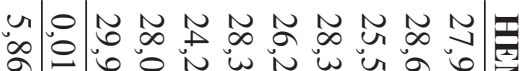

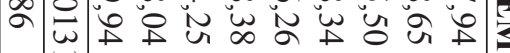

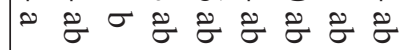

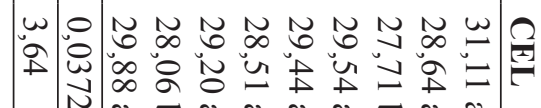

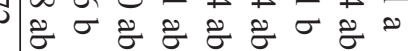

獣

$\stackrel{8}{9}$

- 1 w w

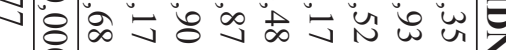

$\rightarrow \begin{array}{llllllll}- & 0 & 0 & 0 & 0 & 0 & 0 & 0\end{array}$

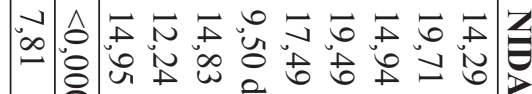

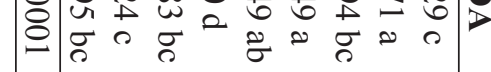




\section{Referências}

ALMEIDA FILHO, S. L.; FONSECA, D. M.; GARCIA, R.; OBEID, A.; OLIVEIRA, J. S. Características agronômicas de cultivares de milho (Zea mays L.) e qualidade dos componentes e silagem. Revista Brasileira de Zootecnia, Viçosa, MG, v. 28, n. 1, p. 7-13, 1999.

CHERNEY, J. H.; CHERNEY, D. J. R. Assessing Silage Quality. In: BUXTON, D. R.; MUCK, R. E.; HARRISON, J. H. (Ed.). Silage science and technology. Madison: American Society of Agronomy, 2003. p. 141198.

DOURADO NETO, D.; PALHARES, M.; VIEIRA, P. A.; MANFRON, P. A.; MEDEIROS, S. L. P.; ROMANO, M. R. Efeito da população de plantas e do espaçamento sobre a produtividade de milho. Revista Brasileira de Milho e Sorgo, Sete Lagoas, v. 2, n. 3, p. 63-77, 2003.

EMPRESA BRASILEIRA DE PESQUISA AGROPECUÁRIA - EMBRAPA. Sistema Brasileiro de Classificação de Solos. Seminário Nacional de Levantamento e Conservação de Solos. Brasília: EMBRAPA, 2006. 306 p.

FERNANDES, F. C. S.; BUZETTI, S.; ARF, O.; ANDRADE, J. A. C. Doses, eficiência e uso de nitrogênio por seis cultivares de milho. Revista Brasileira de Milho e Sorgo, Sete Lagoas, v. 4, n. 2, p. 195-204, 2005.

FLARESSO, J. A.; GROSS, C. D.; ALMEIDA, E. D. Cultivares de milho (Zea mays L.) e Sorgo (Sorghum bicolor (L.) Moench.) para ensilagem no alto Vale do Itajaí, Santa Catarina. Revista Brasileira de Zootecnia, Viçosa, MG, v. 29, n. 6, p. 1608-1615, 2000.

JAREMTCHUK, A. R.; JAREMTCHUK, C. C.; BAGLIOLI, B.; MEDRADO, M. T.; KOZLOWSKI, L. A.; COSTA, C.; MADEIRA, H. M. F. Características agronômicas e bromatológicas de vinte genótipos de milho (Zea mays L.) para silagem na região leste paranaense. Acta Scientiarum, Maringá, v. 27, n. 2, p. 181-188, 2005.

JOBIM, C. C.; NUSSIO, L. G.; REIS, R. A.; SCHMIDT, P. Avanços metodológicos na avaliação da qualidade da forragem conservada. Revista Brasileira de Zootecnia, Viçosa, MG, v. 36, p. 101-119, 2007. Suplemento Especial.

KUNG JÚNIOR, L.; GRIEVE, D. B.; THOMAS, J. W.; HUBER, J. T. Added ammonia or microbial inoculant for fermentation and nitrogenous compounds of alfalfa ensiled at various percents of dry matter. Journal of Dairy Science, Champaign, v. 67, n. 2, p. 299-306, 1984.
LICITRA, G.; HERNANDEZ, T. M.; VAN SOEST, P. J. Standardization of procedures for nitrogen fractionation of ruminant feeds. Animal Feed Science and Technology, Amsterdam, v. 57, n. 4, p. 347-358, 1996.

MCDONALD, P.; HENDERSON, N.; HERON, S. The biochemistry of silage. 2. ed. New York: Chalcombe Publications, 1991. $339 \mathrm{p}$.

NUSSIO, L. G. Cultura de milho para produção de silagem de alto valor alimentício. In: SIMPÓSIO SOBRE NUTRIÇÃO DE BOVINOS, 4., 1991, Piracicaba. Anais... Piracicaba: Escola Superior de Agricultura Luiz de Queiroz, 1991. p. 59-168.

Produção de silagem de alta qualidade. In: REUNIÃO NACIONAL DE MILHO E SORGO, 19., 1992, Porto Alegre. Anais... Porto Alegre: Secretaria de Agricultura e Abastecimento, 1992. p. 155-175.

PAZIANI, S. F.; DUARTE, A. P.; NUSSIO, L. G.; GALLO, P. B.; BITTAR, C. M. M.; ZOPOLLATTO, M.; RECO, P. C. Características agronômicas e bromatológicas de híbridos de milho para produção de silagem. Revista Brasileira de Zootecnia, Viçosa, MG, v. 38, n. 3, p. 411-417, 2009.

PINTO, A. P.; LANÇANOVA, A. C.; LUGÃO, S. M. B.; ROQUE, A. P.; ABRAHÃO, J. J. S.; OLIVEIRA, J. S. S.; LEME, M. C. J.; MIZUBUTI, I. Y. Avaliação de doze cultivares de milho (Zea mays L.) para silagem. Semina: Ciências Agrárias, Londrina, v. 31, n. 4, p. 1071-1078, 2010.

PLAYNE, M. J.; MCDONALD, P. The buffering constituents of herbage and of silage. Journal of the Science of Food and Agricultural, Oxford, v. 17, n. 6, p. 264-268, 1966.

RABÊLO, F. H. S.; REZENDE, A. V.; RABELO, C. H. S.; AMORIM, F. A. Características agronômicas e bromatológicas do milho submetido a adubações com potássio na produção de silagem. Revista Ciência Agronômica, Fortaleza, v. 44, n. 3, p. 635-643, 2013.

REIS, A. R.; JOBIM, C. C. Perfil da fração de carboidratos da planta e adequação de aditivos no processo de ensilagem. In: WORKSHOP SOBRE MILHO PARA SILAGEM, 2., 2000, Piracicaba. Anais... Piracicaba: Escola Superior de Agricultura Luiz de Queiroz, 2000, p. 27-52.

ROSA, J. R. P.; SILVA, J. H. S.; RESTLE, J.; PASCOAL, L. L.; BRONDANI, I. L.; ALVES FILHO, D. C.; FREITAS, A. K. Avaliação do comportamento agronômico da planta e valor nutritivo da silagem de diferentes híbridos de milho (Zea mays L.). Revista Brasileira de Zootecnia, Viçosa, MG, v. 33, n. 2, p. 302312, 2004. 
STATISTICAL ANALYSIS SYSTEM INSTITUTE - SAS. Institute Inc. Statistical analysis system user's guide. Version 9.0. Cary, Statistical Analysis System Institute, $2002.513 \mathrm{p}$.

SILVA, D. J.; QUEIROZ, A. C. Análise de alimentos: métodos químicos e biológicos. Viçosa, MG: UFV, 2002. $235 \mathrm{p}$.

VAN SOEST, P. J.; ROBERTSON, J. B.; LEWIS, B. A. Methods for dietary fiber, neutral detergent fiber, and nonstarch polysaccharides in relation to animal nutrition. Journal of Dairy Science, Champaign, v. 74, n.10, p. 3583-3597, 1991.

VAN SOEST, P. J. Nutritional ecology of the ruminant. 2. ed. Ithaca: Cornell University, Ithaca, 1994. 476 p.
VIEIRA, P. F. Efeito do formaldeído na proteção de proteína e lipídeos em ração para ruminantes. 1980. Tese (Doutorado em Zootecnia) - Universidade Federal de Viçosa, Viçosa, MG.

ZEOULA, L. M.; BELEZE, J. R. F.; CECATO, U.; JOBIM, C. C.; GERON, L. J. V.; MAEDA, E. M.; FALCÃO, A. J. S. Avaliação de cinco híbridos de milho (Zea mays, L.) em diferentes estádios de maturação. 3. Composição químico-bromatológica. Revista Brasileira de Zootecnia, Viçosa, MG, v. 32, n. 3, p. 556-566, 2003.

ZOPOLLATTO, M.; NUSSIO, L. G.; PAZIANI, S. F.; RIBEIRO, J. L.; SARTURI, J. O; MOURÃO, G. B. Relações biométricas entre o estádio de maturação e a produtividade de híbridos de milho para produção de silagem. Revista Brasileira de Zootecnia, Viçosa, MG, v. 38, n. 2, p. 256-264, 2009. 
